\title{
FEASIBILITY OF PERIPHERAL INTRAVENOUS ACCESS IN NEONATES IN THE DELIVERY ROOM AN OBSERVATIONAL STUDY
}

C. Boithias ${ }^{1}, \underline{\text { M. Benlaida }}{ }^{1}$, L. Julé1, N. Le Saché1, M. Mokhtari1 ${ }^{1}$, U. Lausten-Thomsen ${ }^{1}$, P. Tissières ${ }^{1,2}$.

1South Paris University Hospitals. Medical center Bicetre, Pediatric intensive care unit and neonatal medecine, Le Kremlin Bicetre, France.

2Paris Saclay University, Institut of integrative biology of the cell, Gif sur Yvette, France.

\section{Background and Aims}

Venous access remains challenging for small/sick newborns. The optimal route for gaining venous access is debatable. We explored the feasibility and time needed for gaining peripheral venous access in the delivery room.

\section{Method}

A prospective, observational study over 12 months on all neonates requiring hospitalization directly from the delivery room was conducted at our level III neonatal department. Data on diagnosis, provider, time, number of attempts, and site of puncture was recorded.

The performers were junior doctors, senior neonatologists, or nurses. The choice of performer and methods was made by the team present at the given time. No transillumination or ultrasound was used.

\section{Results}

Of the 413 included neonates, 269 indicated peripheral intravenous access (glucose infusion $78 \%$, sedative drugs $17 \%$, antibiotics $4 \%$, others $1 \%$ ). Mean gestational age was 33 weeks +3 days (range $26+0-41+1$ ) and mean birth weight, $1948 \mathrm{~g}$ (range 500-4700).

The overall success rate was $95 \%$. Meantime for obtaining venous access was 5.2 (+/- 4.6) minutes. The mean post-natal age was 38.0 $(+/-25 \mathrm{~m}$ minutes).

Mean number of attempts was 1.9 (range 1-6). Intravenous access was obtained by junior $(39 \%)$ or senior neonatologists $(58 \%)$, or nurses $(3 \%)$. The individual overall success rate was $45 \%$ (junior doctors), 61\% (senior doctors), and $40 \%$ (nurses) respectively. As no randomization was done, the success rates cannot be directly compared.

Reason for use of the peripheral intravenous
access

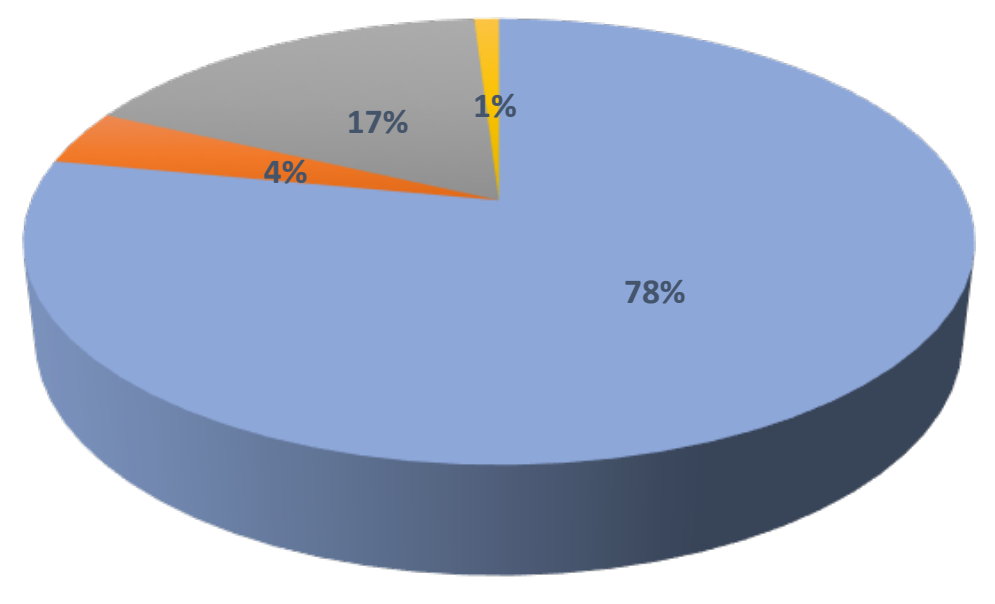

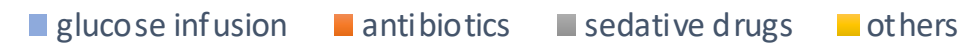
individual overall success rate

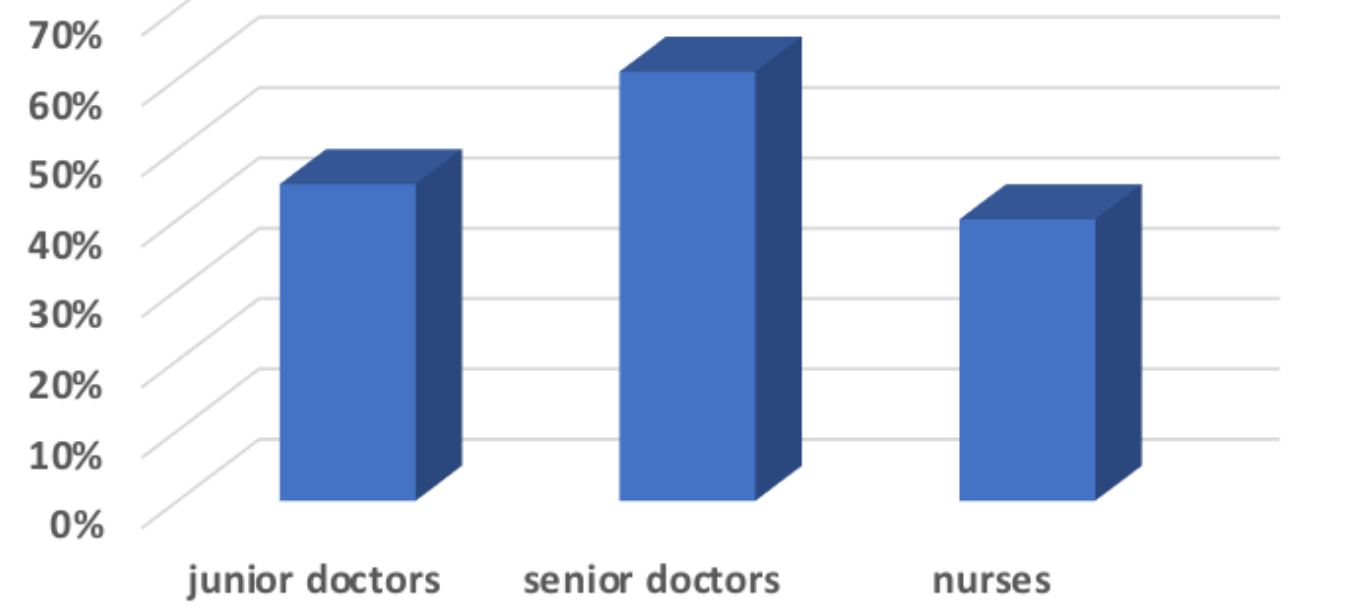

\section{Conclusion}

We demonstrated the feasibility and high overall success rate in obtaining peripheral intravenous access, even in very small and sick neonates. Additionally, in this study, the mean number of attempts and time consumption was low. 